\title{
NOVEL TECHNIQUE FOR PERFORMING RETROGRADE PYELOGRAM THROUGH A URETERIC STENT \\ Jonathan Cobley ${ }^{1}$ MBBCh MRCS and Wasim Mahmalji ${ }^{1}$ MBBS FRCS \\ ${ }^{1}$ Hereford County Hospital, Stonebow Road, Hereford, UK.
}

Corresponding author: jonathan.cobley@nhs.net

Submitted: March 8, 2017. Accepted: March 9, 2018. Published: June 2, 2018.

A female was diagnosed with kidney stones in Nepal and treated with ureteroscopy and lasertripsy for a left ureteric stone. She moved to the UK and was referred for urology opinion with left-sided abdominal pain.

Non-contrast computed tomography of the renal tract (CT KUB) showed a 5-6 mm calculus below the left pelviureteric junction (PUJ) and multiple lower pole calculi. At ureteroscopy appearances were of a long-term ureteric stone which had the middle of it lasered in Nepal. Subequently, urothelium had started healing over the remaining portion.

This was lasered to allow passage of a 6 French, 24-cm ureteric stent to be left in situ prior to re-look ureteroscopy. At second look ureteroscopy the stricture appeared improved and with flexible ureteroscopy the kidney was successfully cleared of stones. A stent was left and subsequently removed without difficulty two weeks later. Subsequent CT urogram showed an obstructed left kidney secondary to a stricture and the patient complained of left-sided pain once again.

\section{POINT OF TECHNIQUE}

Retrograde pyelogram was attempted but no contrast made it beyond the stricture (see Figure 1). There was a pinhole stricture through which a guidewire was passed with great difficulty and it was impossible to pass 6 French ureteric catheter through the stricture. Due to the severity of the stricture it was of paramount importance to place a stent and to ensure its correct placement however there was no retrograde pyelogram for anatomical confirmation.

To overcome this problem a 4.8 French multi-length stent was placed over the wire, again with difficulty. Using biopsy forceps we pulled the distal end of the

FIG. 1 (A) Coronal view of contrast-enhanced CT in urographic phase showing hydronephrotic left kidney. (B) Attempted retrograde pyelogram with failure of contrast to pass stricture. (C) Successful retrograde pyelogram via 4.8 French multi-length stent.

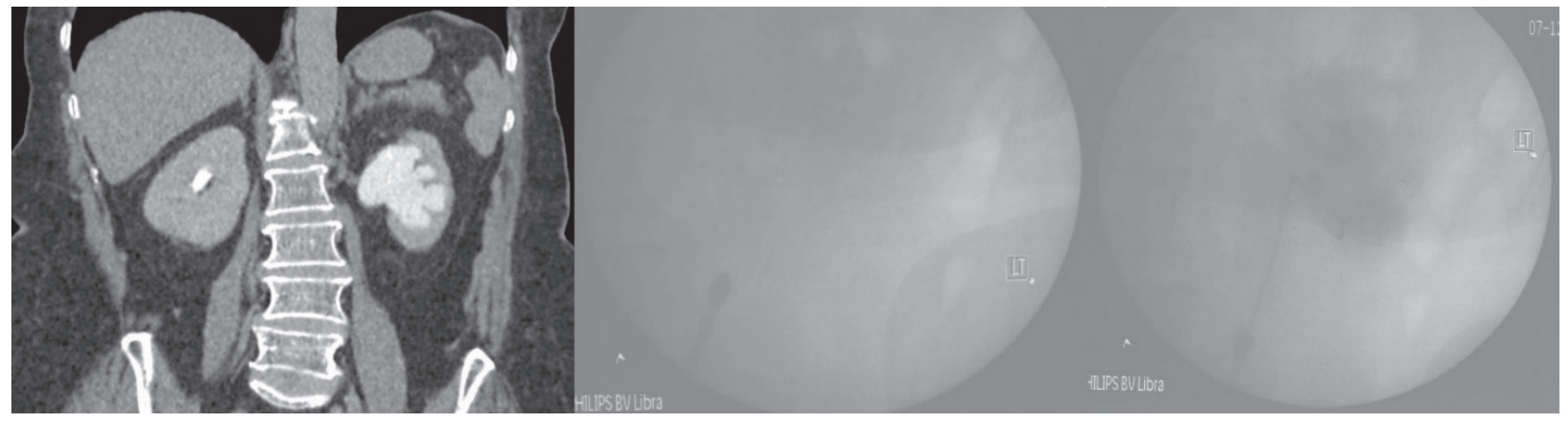

J Endolum Endourol Vol 1(1):e28-e29; June 2, 2018.

This article is distributed under the terms of the Creative Commons Attribution-Non Commercial 4.0 International License. CCobley and Mahmalji 2018. 
stent to the urethral meatus and screened with the image intensifier to confirm that the proximal stent end remained in an appropriate position bypassing the stricture. We then detached the injection hub from the ureteric catheter and attached it to the stent (Figure 2), allowing us to perform a retrograde pyelogram via the lumen of the stent, before reinserting the guidewire to the kidney and advancing the stent. This was effective and conferred no additional cost to the procedure.

FIG. 2 (A) Multi-length ureteric stent (http://www.bostonscientific.com/en-US/products/stents--ureteral/ contour.html). (B) Injection hub from Boston Scientific ureteric catheter which was detached and applied to a 4.8 French multi-length stent (http://www.bostonscientific.com/en-US/products/catheters--ureteral/ axxcess.html).
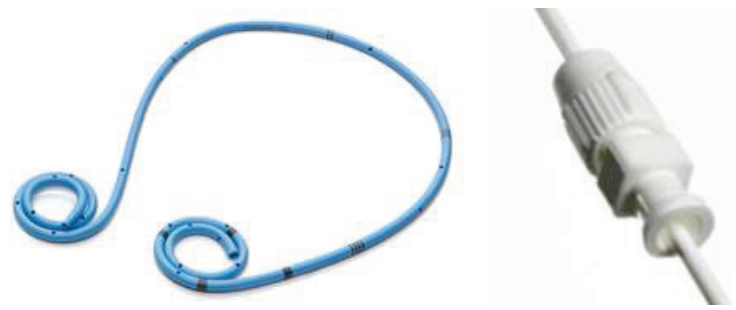

This technique is useful in cases where a ureteric stricture precludes contrast passing retrograde up to the kidney and is too tight to allow passage of a 6 French ureteric catheter. Use of a multi-length stent is vital to allow maximum internal length when pulling the distal end to the urethral meatus. This is the main limitation which may preclude use on males, due to their longer urethras, however it may be possible in very distal ureteric strictures.

\section{DISCLOSURE}

The authors have no competing interests to declare. 